\title{
Notch4 mediates vascular remodeling via ERK/JNK/P38 MAPK signaling pathways in hypoxic pulmonary hypertension
}

Mingzhou Guo 1,2, Mengzhe Zhang 1,2, Xiaopei Cao ${ }^{3}$, Xiaoyu Fang ${ }^{1,2}, \mathrm{Ke} \mathrm{Li}^{1,2}, \mathrm{Lu}$ Qin ${ }^{1,2}$, Yuanzhou He ${ }^{1,2}$, Jianping Zhao ${ }^{1,2}$, Yongjian $\mathrm{Xu}^{1,2}$, Xiansheng $\mathrm{Liu}^{1,2}$ and Xiaochen $\mathrm{Li}^{1,2^{*}}$

\begin{abstract}
Background: Hypoxic pulmonary hypertension $(\mathrm{HPH})$ is a chronic progressive advanced disorder pathologically characterized by pulmonary vascular remodeling. Notch4 as a cell surface receptor is critical for vascular development. However, little is known about the role and mechanism of Notch4 in the development of hypoxic vascular remodeling.

Methods: Lung tissue samples were collected to detect the expression of Notch4 from patients with HPH and matched controls. Human pulmonary artery smooth muscle cells (HPASMCs) were cultured in hypoxic and normoxic conditions. Real-time quantitative PCR and western blotting were used to examine the mRNA and protein levels of Notch4. HPASMCs were transfected with small interference RNA (siRNA) against Notch4 or Notch4 overexpression plasmid, respectively. Cell viability, cell proliferation, apoptosis, and migration were assessed using Cell Counting Kit-8, Edu, Annexin-V/PI, and Transwell assay. The interaction between Notch4 and ERK, JNK, P38 MAPK were analyzed by co-immunoprecipitation. Adeno-associated virus 1-mediated siRNA against Notch4 (AAV1-si-Notch4) was injected into the airways of hypoxic rats. Right ventricular systolic pressure (RVSP), right ventricular hypertrophy and pulmonary vascular remodeling were evaluated.
\end{abstract}

Results: In this study, we demonstrate that Notch4 is highly expressed in the media of pulmonary vascular and is upregulated in lung tissues from patients with $\mathrm{HPH}$ and HPH rats compared with control groups. In vitro, hypoxia induces the high expression of Delta-4 and Notch4 in HPASMCs. The increased expression of Notch4 promotes HPASMCs proliferation and migration and inhibits cells apoptosis via ERK, JNK, P38 signaling pathways. Furthermore, co-immunoprecipitation result elucidates the interaction between Notch4 and ERK/JNK/P38. In vivo, silencing Notch4 partly abolished the increase in RVSP and pulmonary vascular remodeling caused by hypoxia in HPH rats.

Conclusions: These findings reveal an important role of the Notch4-ERK/JNK/P38 MAPK axis in hypoxic pulmonary remodeling and provide a potential therapeutic target for patients with $\mathrm{HPH}$.

Keywords: Hypoxic pulmonary hypertension, Human pulmonary arterial smooth muscle cells, Notch4, Mitogenactivated protein kinase

\footnotetext{
*Correspondence: lixiaochen3n2b@163.com

${ }^{1}$ Department of Pulmonary and Critical Care Medicine, Tongji Hospital,

Tongji Medical College, Huazhong University of Science and Technology, 1095 Jiefang Avenue, Wuhan 430030, China

Full list of author information is available at the end of the article
}

\section{Background}

Pulmonary hypertension $(\mathrm{PH})$ is a pathophysiological disorder characterized by increased pulmonary vascular resistance and pulmonary arterial pressure [1]. Pulmonary vascular remodeling is an important contributor to 
increased pulmonary vascular resistance. The process of pulmonary vascular remodeling involves excessive proliferation, migration, and apoptosis resistance of pulmonary artery smooth muscle cells (PASMCs) in the media of the pulmonary artery $[2,3]$. The patients with $\mathrm{PH}$ due to chronic lung disease and/or hypoxia are classified as group III PH, mainly secondary to chronic obstructive pulmonary disease, interstitial lung disease, and so on [4]. These patients complicated with $\mathrm{PH}$ are usually diagnosed at end-stage with a poor prognosis. However, the benefits of current treatment on the prognosis of those patients remain limited. So far, the pathogenesis of hypoxic pulmonary vascular remodeling has not been fully elucidated.

The Notch4 protein is a member of the Notch family, a set of four transmembrane proteins (Notch1-4) that share a similar structure, but differ in their cellular localization and tissue distribution [5]. In all members of the Notch receptors, ligand binding triggers proteolytic receptor cleavage to release the Notch intracellular domain. Then the Notch intracellular domain translocates to the nucleus where it binds to the CSL family of DNA-binding proteins and forms a transcriptional activator to activate Notch target genes [6-10]. Notch4 serves as a membrane-bound receptor that regulates cell fate [11]. Notch4 activation in endothelial cells promotes epithelial-mesenchymal transition, which is required for normal endocardial cushion differentiation and vascular smooth muscle cell development [12]. In addition, Notch4 plays an important role in promoting carcinogenesis and metastasis in several types of tumors [1315]. However, the role of Notch 4 in the smooth muscle cells remains unclear.

In certain context, Notch crosstalk with numerous pathways, such as Akt, TGF- $\beta$ and src signaling [16-18]. Protein phosphorylation is one of the most important post-translational modifications regulating various signaling transduction. Mitogen-activated protein kinase (MAPK) members including ERK, JNK, and P38 kinases $[19,20]$. These serine-threonine protein kinases play critical roles in the regulation of many cellular processes including cell cycle, proliferation, and apoptosis [21, 22]. Previous studies have shown that hypoxia promoted cell proliferation and inhibited apoptosis of PASMCs and sequentially induced pulmonary vascular remodeling via phosphorylated activation of ERK, JNK, and P38 signaling pathways [23-25]. Several studies have demonstrated that Notch4 was involved in the regulation of survival and migration of tumor and endothelial cells via MAPK signaling pathways [26-29]. This study aims to elucidate the role and molecular mechanism of Notch4 in hypoxic pulmonary arterial smooth muscle cells through in vitro and in vivo models.

\section{Methods Clinical samples}

A group of surgical lung tissues were collected from 4 $\mathrm{PH}$ patients including 2 patients with $\mathrm{PH}$ secondary to chronic obstructive pulmonary disease and 2 patients with $\mathrm{PH}$ related to interstitial lung disease, and 4 patients without PH in the control group. According to the previous method in the study on $\mathrm{PH}$ [30], lung tissues from the control patients were commonly collected at a site remote from tumor foci.

All patients were enrolled from Tongji Hospital of Huazhong University of Science and Technology (Wuhan, China). This study was approved by the Ethics Committee of Tongji Hospital. Written informed consent was obtained from each patient.

\section{Cell lines and cultures}

HPASMCs were obtained from Procell Life Science \& Technology Corporation. All cells were cultured in Dulbecco's Modified Eagle Medium supplemented with 10\% fetal bovine serum and maintained in a humidified incubator with $5 \% \mathrm{CO}_{2}$ at $37^{\circ} \mathrm{C}$. The hypoxic HPASMCs were cultured in a $5 \% \mathrm{O}_{2}$ incubator (Galaxy R; RS Bitotech, Alloa, UK) continually gassed with $5 \% \mathrm{CO}_{2}$ and $90 \% \mathrm{~N}_{2}$.

\section{Antibodies and chemicals}

The antibodies against proliferating cell nuclear antigen (PCNA), Bcl-2 associated X (Bax), survivin, matrix metallopeptidase 9 (MMP9), matrix metallopeptidase 2 (MMP2), $\beta$-Actin and normal rabbit or mouse immunoglobulin G (IgG) were obtained from Proteintech (Wuhan, Hubei, China). B cell leukemia/lymphoma 2 (Bcl-2) antibody was obtained from Boster (Wuhan, Hubei, China). P38, p-P38, JNK, p-JNK, ERK, p-ERK antibodies, and Protein G magnetic beads were obtained from Cell Signaling Technology (Danvers, MA, USA). Anti-Notch4 was obtained from Santa Cruz Biotechnology (Dallas, Texas, USA). HRP-conjugated anti-Rabbit IgG and HRP-conjugated anti-Mouse IgG were obtained from Servicebio (Wuhan, Hubei, China). HRP-conjugated anti-Rabbit IgG light chain and HRP-conjugated anti-mouse IgG light chain were obtained from Abbkine Scientific (Redlands, CA, USA). U0126, SP600125 and SB203580 were obtained from MedChemExpress (Monmouth Junction, NJ, USA). 


\section{Cell transfection}

Small interfering RNAs (siRNAs) against Notch4 and negative control siRNA were synthesized by RiboBio (Guangzhou, China). HPASMCs were transfected with siRNAs using Lipofectamine 3000 (Invitrogen, Carlsbad, CA) according to the manufacture's instruction. The siRNA against Notch4 sequence was as follows: CAACGGGCACUGUGAGAAA. When reaching $40-60 \%$ of confluence, the cells were transfected with 50 nmol siRNA using Lipofectamine 3000. Notch4 overexpression plasmid and negative control plasmid were synthesized by GeneChem (Shanghai, China). The mammalian expression plasmid for Flag-tagged Notch4 was constructed by molecular cloning. The construct was confirmed by DNA sequencing. When reaching $80-90 \%$ of confluence, the cells were transfected with $1 \mu \mathrm{g}$ purified plasmid. Finally, the mRNA and protein levels of cells were analyzed by quantitative real-time PCR and western blotting at $48 \mathrm{~h}$ and $72 \mathrm{~h}$ after transfection, respectively.

\section{Cell viability assay}

Cell viability was measured using the Cell Counting Kit-8 assay. HPASMCs were seeded into 96-well plates at the cell density of 3000 cells per well for $24 \mathrm{~h}$. Then the medium was replaced with different transfection mixture. After $6 \mathrm{~h}$ incubation, the transfection mixture was replaced with medium supplemented with $10 \%$ fetal bovine serum, and the cells were further incubated for $24 \mathrm{~h}$. After that, cells were incubated under normoxic or hypoxic conditions for $24 \mathrm{~h}$. Finally, $10 \mu \mathrm{L}$ Cell Counting Kit-8 (Dojindo, Japan) reagent was added into per well and optical density in each well was determined by an ELx800 Universal Microplate Reader (BioTek Instruments, Winooski, VT, USA).

\section{Edu proliferation assay}

HPASMCs were seeded into 96-well plates (3000 cells per well) and cultured in normoxic or hypoxic conditions as mentioned above. Cell proliferation was assessed using Edu Cell Proliferation Assay Kit (RiboBio, Cell-Light ${ }^{\mathrm{TM}}$ Edu Apollo ${ }^{\circledR} 643$ In Vitro imaging kit), according to the manufacture's instruction. The cells were added with $100 \mu \mathrm{L}$ Edu (diluent reagent A with a complete medium by $1: 1000$ ) and incubated for $2 \mathrm{~h}$ at $37{ }^{\circ} \mathrm{C}$. Then cells were fixed in $4 \%$ paraformaldehyde for $15-30 \mathrm{~min}$ and incubated with $1 \times$ Apollo $^{\circledR}$ solution for another $30 \mathrm{~min}$ at room temperature. Cell nuclei were stained with $100 \mu \mathrm{L} 1 \times$ Hoechst33342 for $30 \mathrm{~min}$.
Finally, the cells were examined under a fluorescent microscope (Olympus, Japan). Data were shown as fold-change increase in the percentage of Edu-incorporating cells in treated cells, compared with negative controls.

\section{Cell apoptosis assay}

HPASMCs were seeded into a 6-well plate $(100,000$ cells per well). Firstly, cells were starved in serum-free for $24 \mathrm{~h}$. After transfection for $48 \mathrm{~h}$, cells were exposed to normoxic or hypoxic conditions for another $24 \mathrm{~h}$. Then cells were collected and resuspended in $200 \mu \mathrm{L}$ binding buffer per well. The cells were labeled with $5 \mu \mathrm{L}$ Annexin$\mathrm{V}$ and propidium iodide (PI) to assess cell apoptosis using an Annexin-V/PI detection kit (Keygen Biotech, Nanjing, China). Finally, apoptotic cells were analyzed using flow cytometry (BD Biosciences, SanJose, CA). Apoptotic cells including early apoptotic cells (Annexin-V positive and PI-negative) and late apoptotic cells (Annexin-V positive and PI-positive) were shown.

\section{Cell migration assay}

Cell migration assay was performed in a 24-well plate (Corning, MA, USA) according to the manufacture's instruction. Firstly, $200 \mu \mathrm{L}$ cell suspensions (10,000 cells totally) containing $1 \%$ fetal bovine serum were seeded into the upper chamber, while $600 \mu \mathrm{L}$ medium containing $15 \%$ fetal bovine serum were added into lower chambers. The cells were cultured in normoxic or hypoxic condition for $24 \mathrm{~h}$. Then cells on the lower surface of the membrane were fixed with $4 \%$ paraformaldehyde and stained with $0.1 \%$ crystal violet. Non-migrated cells were removed by scraping the membranes with a cotton swab from the upper surface. Finally, cells were counted under an optical microscope (Zeiss, Oberkochen, Germany).

\section{RNA extraction and real-time quantitative PCR}

Total RNA was isolated using Trizol (Takara, Dalian, China) according to the manufacture's instruction. RNA concentration was determined by Nanodrop analysis. cDNA was synthesized from total RNA using PrimeScript RT reagent kit (Takara, Dalian, China). Quantitative RT-PCR was performed using SYBR Green Mix (Takara, Dalian, China). The primer sequences were as follows: Notch4 forward, 5'-CGTACCCCACTTCAC ACTGC-3', reverse, 5'-AGGTGTAGTCCCGTCGTC TG-3'. 
Table 1 Clinical characteristic of control patients

\begin{tabular}{lll}
\hline & Sex & Diagnosis \\
\hline Patient 1 (P01) & Female & Adenocarcinoma \\
Patient 2 (P02) & Female & Adenocarcinoma \\
Patient 3 (P03) & Male & Adenocarcinoma \\
Patient 4 (P04) & Female & Adenocarcinoma \\
\hline
\end{tabular}

The cycling conditions were as follows: initial denaturation for $10 \mathrm{~min}$ at $95^{\circ} \mathrm{C}$ followed by 40 cycles of denaturation $\left(15 \mathrm{~s}\right.$ at $\left.95{ }^{\circ} \mathrm{C}\right)$, annealing and elongation $(30 \mathrm{~s}$ at $\left.60{ }^{\circ} \mathrm{C}\right)$. The relative expression of gene was calculated using $2^{-\triangle \triangle \mathrm{Ct}}$ method using $\beta$-Actin as the reference gene.

\section{Western blotting analysis}

Total cellular protein was extracted by RIPA lysis buffer (50 mM Tris, $150 \mathrm{mM} \mathrm{NaCl}, 1 \% \mathrm{NP}-40,0.5 \%$ sodium deoxycholate, $0.1 \%$ SDS, PH7.4) supplemented with phenylmethylsulfonyl fluoride, cocktail, and phosphorylation protease inhibitor. Cell lysis was centrifuged at $12,000 \mathrm{rpm}$ for $15 \mathrm{~min}$ and the supernatants were collected for determination of the protein concentration by BCA assay. All steps were performed at $4{ }^{\circ} \mathrm{C}$. Then $50 \mu \mathrm{g}$ of protein were subjected to $10 \%$ sodium dodecyl sulfate-polyacrylamide gel electrophoresis followed by western blotting. The signals were detected using a chemiluminescent substrate system (Bio-Rad, Hercules, CA, USA). Relative expressions of target proteins were quantified by Image $\mathrm{J}$ software.

\section{Co-immunoprecipitation assay}

Co-immunoprecipitation experiments were performed according to a standard protocol. Briefly, cells were harvested and lysed in IP-lysis buffer (50 mM Tris, $150 \mathrm{mM}$ $\mathrm{NaCl}, 1 \% \mathrm{NP}-40)$ and protease inhibitor. Supernatants were collected by microcentrifuge $(14,000 \mathrm{rpm}, 10 \mathrm{~min}$, $4{ }^{\circ} \mathrm{C}$ ), and pre-cleared with $20 \mu \mathrm{L}$ Protein G Magnetic beads (Cell Signaling Technology) for $2 \mathrm{~h}$. Then the pre-cleared supernatants were incubated with primary antibodies $(2 \mu \mathrm{g} / \mathrm{mL})$ rotated overnight at $4{ }^{\circ} \mathrm{C}$ to form an immunocomplex. Then transferred immunocomplex solution to the tube containing pre-washed magnetic beads and incubated rotated for $3-4 \mathrm{~h}$ at $4{ }^{\circ} \mathrm{C}$. Finally, the immunocomplex was washed five times with 500 $\mu \mathrm{L}$ of $1 \times$ cell lysis buffer and analyzed by western blotting analysis.

\section{Immunohistochemistry}

Formalin-fixed, paraffin-embedded tissue sections were de-waxed and antigen retrieval with citrate buffer $(\mathrm{PH}=6.0)$. Then sections were incubated in $3 \%$ hydrogen peroxide for $20 \mathrm{~min}$ at room temperature to block endogenous peroxidase, followed by blocked in 5\% bovine serum for $40 \mathrm{~min}$. Primary antibodies were added to sections and incubated overnight at $4{ }^{\circ} \mathrm{C}$ in a humidified chamber, then incubated with secondary antibody for $40 \mathrm{~min}$ at room temperature. For immunohistochemistry analysis, the sections were further incubated with the avidin-biotin-peroxidase complex, which was detected with diaminobenzidine. Finally, sections were counterstained by hematoxylin, dehydrated in graded ethanol, and mounted with Permount.

(See figure on next page.)

Fig. 1 Notch4 expression is upregulated in lung tissues from patients with HPH and controls. Lung tissues were obtained from patients with confirmed HPH $(n=4)$ and matched control non-PH patients. $(n=4)$ A Protein levels of Notch4 in lung tissues from patients with HPH and without $\mathrm{PH}$. B Notch4 (red) and a-SMA (green) immunofluorescence staining in small pulmonary arteries from humans with HPH (P08) or non-PH (P01). Nuclei are counterstained with DAPI (blue). Magnification, $\times 400 ;$ Bar, $20 \mu \mathrm{m}$. Data were presented as means \pm SD. ${ }^{*} P<0.05$. Student's t-test was performed for $\mathbf{A}$. PH, pulmonary hypertension; HPH, hypoxic pulmonary hypertension; a-SMA, a-smooth muscle actin 

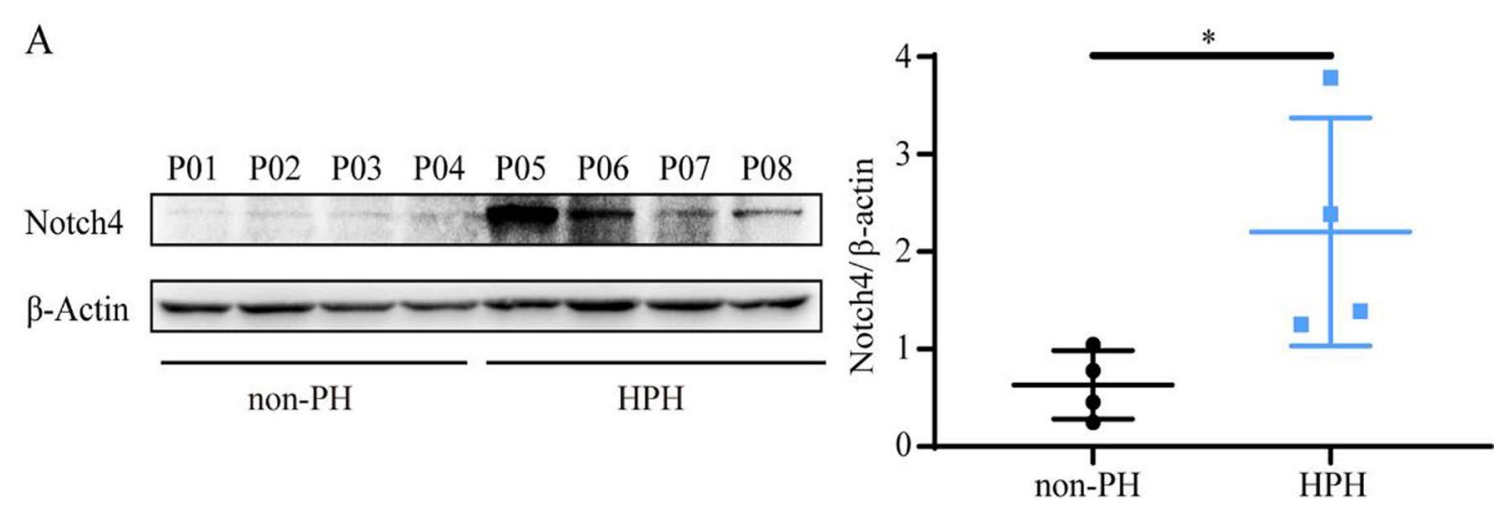

B

HPH (P08)

non-PH (P01)
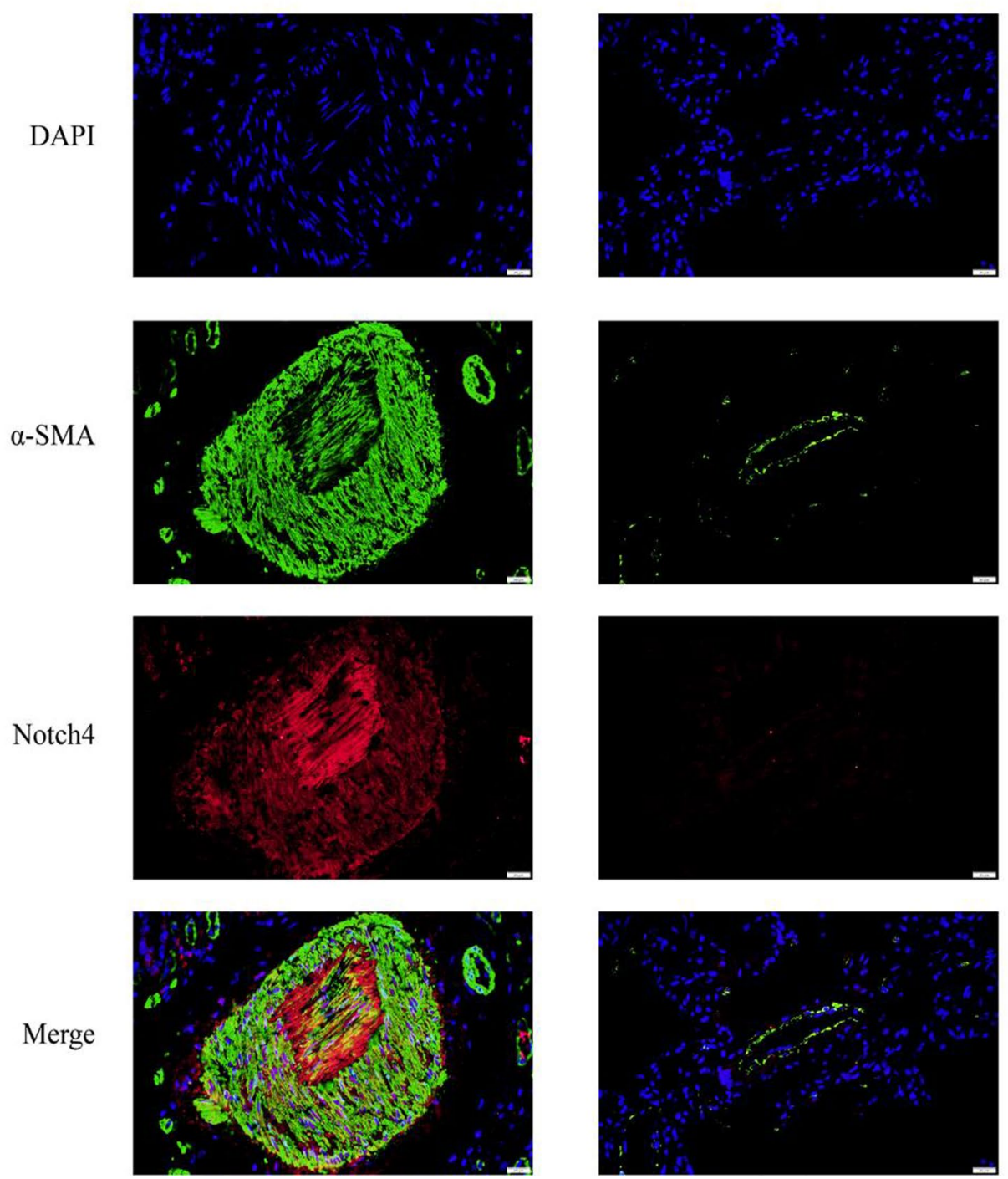

Fig. 1 (See legend on previous page.) 
Table 2 Clinical characteristic of HPH patients

\begin{tabular}{llllllc}
\hline & Sex & Diagnosis & Date of LTx & Age at LTx & $\begin{array}{l}\text { Pre-LTx mPAP } \\
\text { (mmHg) }\end{array}$ & PG (mmHg) \\
\hline Patient 5 (P05) & Female & HPH & $2015 / 07 / 29$ & 28 & NA & NA \\
Patient 6 (P06) & Male & HPH & $2015 / 07 / 04$ & 59 & NA & 34 \\
Patient 7 (P07) & Male & HPH & $2019 / 06 / 02$ & 65 & NA & 35 \\
Patient 8 (P08) & Male & HPH & $2021 / 08 / 17$ & 57 & NA & NA \\
\hline
\end{tabular}

LTx lung transplant, $m P A P$ mean pulmonary arterial pressure, $P G$ tricuspid regurgitation pressure gradient, $H P H$ hypoxic pulmonary arterial hypertension

\section{Immunofluorescence}

Frozen lung sections were fixed with $4 \%$ paraformaldehyde for $15 \mathrm{~min}$. Primary antibodies were added to sections and incubated overnight at $4{ }^{\circ} \mathrm{C}$ in a humidified chamber after blocked with $5 \%$ donkey serum albumin for $1 \mathrm{~h}$. Alexa 594-labeled anti-mouse and Alexa 488-conjugated anti-rabbit antibody (Invitrogen, CA, USA) were used as secondary antibodies. Nuclei were counterstained with DAPI for $5 \mathrm{~min}$.

\section{Animal experiments}

All animal experiments were performed in compliance with the guidelines for animal testing and research, with ethical approval from Tongji Hospital. Adult male Sprague-Dawley rats weighing 200-250 g were fed standard chow and water ad libitum. The rats were exposed to either normoxia or chronic hypoxia $(10 \%$ $\left.\mathrm{O}_{2}\right) 8 \mathrm{~h}$ daily for 5 weeks with a $12 \mathrm{~h}$ light-dark cycle. Hypoxic rats were randomly divided into four groups: hypoxic group $(\mathrm{n}=5)$; AAV1-si-NC group $(100 \mu \mathrm{L}$, $\mathrm{n}=5)$; AAV1-si-Notch4 prophylactic group $(100 \mu \mathrm{L}$, $\mathrm{n}=7)$; AAV1-si-Notch4 therapeutic group $(100 \mu \mathrm{L}$, $\mathrm{n}=6$ ). Hypoxic therapeutic group were intratracheal delivery of AAV1-si-Notch4 after exposed to a hypoxic atmosphere for two weeks. In the prophylactic group,
AAV1-si-Notch4 was delivered at an equivalent dose to rats before exposed to the hypoxic chamber. At 5 weeks, rats were anesthetized with $1 \%$ pentobarbital injection $(120 \mathrm{mg} / \mathrm{kg}$ ip). RVSP was measured via the right jugular vein using a $1.2-\mathrm{F}$ pressure catheter. Then hearts and pulmonary vasculature were perfused with cold saline injection into the right ventricle. Hearts were excised and measured by Fulton's Index (ratio of right ventricle weight to left ventricle plus septum weight, $\mathrm{RV} /[\mathrm{LV}+\mathrm{S}])$. Right lungs were snap-frozen in liquid nitrogen and stored at $-80{ }^{\circ} \mathrm{C}$ for biochemical measurements. Left lungs were perfused with $4 \%$ paraformaldehyde, followed by paraffin embedding. Sections were stained with hematoxylin and eosin and immunohistochemistry for $\alpha$-smooth muscle actin. The medial wall thickness index was calculated as follows: Wall thickness $(\%)=100 \times$ (external diameter - internal diameter)/external diameter.

\section{Statistics}

Statistical analyses were performed using GraphPad Prism version 8.0. Results were plotted as means $\pm S D$. The Student's $t$-test was used for two-sample analyses, and normal distributions were assumed. One-way analysis of variance with Tukey's post hoc test was used for

\footnotetext{
(See figure on next page.)

Fig. 2 Notch4 signaling contributes to hypoxia-induced HPASMCs proliferation, migration and apoptosis resistance. A Cell viability was performed using Cell Counting Kit-8 assay in HPASMCs. $(n=5)$ B, C Cell proliferation was assessed by Edu assay. $(n=3)$ Magnification, $\times 100 ;$ Bar, 100 um. D Cell migration was performed using Transwell assay. Magnification, $\times 100 ;$ Bar, $50 \mu m .(n=4)$ E Cell apoptosis was assessed by Annexin-V/ propidium iodide (PI) staining. Analyses of apoptosis including early apoptosis (Annexin-V positive and PI negative) and late apoptosis (Annexin-V positive and PI positive) were shown. $(n=4)$ F Protein levels of Notch4, MMP9, Bcl-2, Bax, PCNA, survivin were shown. $(n=4)$ Data were presented

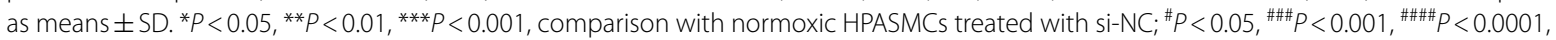
comparison with hypoxic HPASMCs treated with si-NC. One-way ANOVA followed by Tukey's correction for post-hoc comparisons were performed for A-F. CCK-8 cell counting kit-8, si-NC negative control short interfering RNAs (siRNA), si-Notch4 siRNA against Notch4
} 


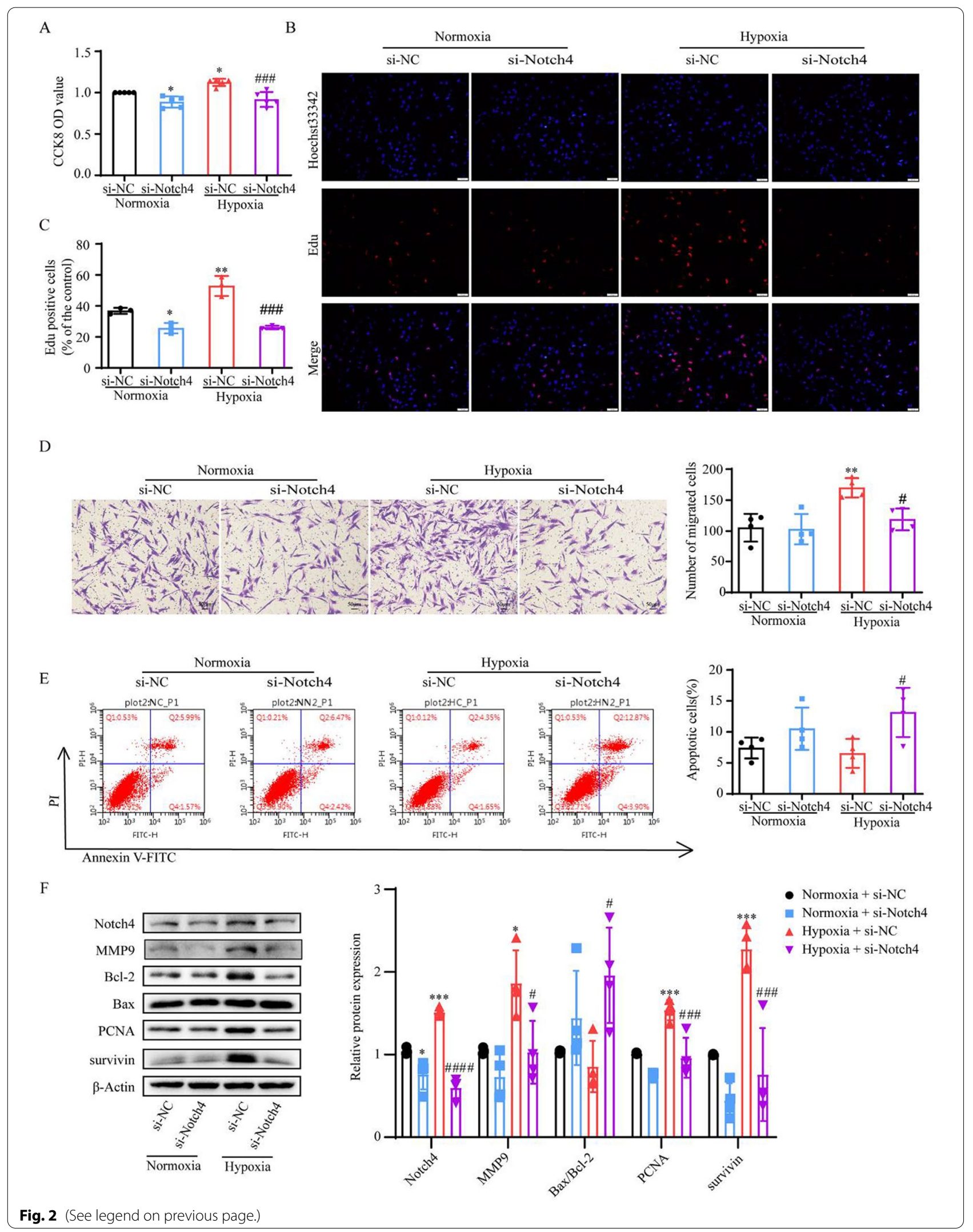


more than two-sample analyses. All experiments were performed at least in triplicate. Significance was considered at the level of $P<0.05$.

\section{Results \\ Notch4 expression is upregulated in HPH patients and HPASMCs under hypoxia}

To investigate the expression of Notch4 in normal and pulmonary hypertensive lungs, we examined lung tissues from 4 individuals with HPH undergoing lung transplantation compared with lung tissues from 4 non-PH individuals (Tables 1,2 ). The protein levels of Notch4 had a tendency to increase in HPH patients compared with non-PH patients (Fig. 1A). Immunofluorescent staining of human lung tissues showed that Notch 4 was localized in the media and intimal layer of small pulmonary arterials. Higher level of Notch4 staining was seen in lung tissues with HPH compared to matched control lung tissues (Fig. 1B). Vascular smooth muscle cells (vSMCs) are the predominant constituents of media. The excessive vSMCs proliferation, migration and apoptosis resistance plays a key role in vascular remodeling in $\mathrm{HPH}$. Therefore, we focus on the function and the underlying mechanisms of Notch4 in HPASMCs isolated from human small pulmonary arteries. Analysis of cultured HPASMCs exposed to normoxia or hypoxia demonstrated that Notch4 mRNA and protein levels were increased under hypoxic conditions and peaked at $3 \mathrm{~h}$ and $24 \mathrm{~h}$, respectively (Additional file 1: Fig. S1A and S1B). Meanwhile, increased mRNA level of Delta-like 4 was also observed in HPASMCs exposed to hypoxia (Additional file 1: Fig. S1D), which may hint that hypoxia induces Notch4 signaling by increasing the levels of Delta-like 4 in HPASMCs.

\section{Notch4 signaling is required for hypoxia-induced HPASMCs} excessive proliferation, migration and apoptosis resistance In our study, hypoxia promoted HPASMCs proliferation and migration, and inhibited cell apoptosis. To assess the role of Notch4 involved in the process in HPASMCs, siRNA against Notch4 were transfected into HPASMCs. The mRNA and protein expression of Notch4 were dramatically decreased following transfection with siRNA against Notch4 in HPAMSCs (Additional file 1: Fig. S2). The knockdown of Notch4 partially abrogated the excessive cell proliferation and migration, and suppressed cell apoptosis resistance under hypoxia (Fig. 2A-E). The levels of proteins associated with cell proliferation (survivin and PCNA), apoptosis (Bax and Bcl-2), and migration (MMP9) were measured in HPASMCs transfected with si-Notch4 or si-NC. Consistently, up-regulation of survivin, PCNA, MMP9, and decreased ratio of $\mathrm{Bax} / \mathrm{Bcl}-2$ were observed in hypoxic HPASMCs and partially abrogated by transfection with siRNA against Notch4 (Fig. 2F). Taken together, these findings indicate that hypoxia-induced HPASMCs proliferation, migration and apoptosis resistance involves Notch4 signaling.

\footnotetext{
(See figure on next page.)

Fig. 3 ERK, JNK, and P38 MAPK signaling mediate the regulation of Notch4 on HPASMCs proliferation, apoptosis, and migration. A The MAPK signaling pathway were detected in HPASMCs transfected with siRNA against Notch4 or negative control siRNA. $(n=3-6)$ B Cell viability was examined in HPASMCs transfected with Notch4 plasmid or negative control plasmid together with ERK (U0126), JNK (SP600125), or P38 (SB203580) MAPK pathway inhibitors by using Cell Counting Kit-8 assay. $(n=4)$ C, D Proliferation was assessed by Edu assay in HPASMCs

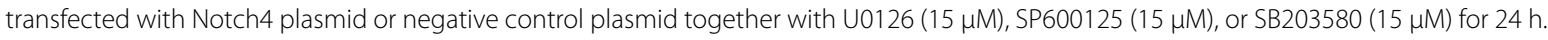
$(n=4)$ Magnification, $\times 100 ;$ Bar, 100 um. E, F Migration was determined in HPASMCs transfected with Notch4 plasmid or negative control plasmid together with U0126, SP600125, or SB203580 for 24 h. Magnification, $\times 100$; Bar, 50 m. $(n=3)$ G, H The Annexin-V/PI assay was performed in HPASMCs transfected with Notch4 plasmid or negative control plasmid together with U0126, SP600125, or SB203580 for 24 h. Analyses of apoptosis including early apoptosis (Annexin-V positive and PI negative) and late apoptosis (Annexin-V positive and PI positive) were shown. $(n=4)$ Data were presented as means \pm SD. ${ }^{*} P<0.05$, ${ }^{*} P<0.01$, ${ }^{* *} P<0.001$, ${ }^{* * *} P<0.0001$, comparison with normoxic HPASMCs treated with si-NC; ${ }^{*} P<0.05$, $\# P<0.01$, \#\#\# $P<0.001$, comparison with hypoxia HPASMCs treated with si-NC. One-way ANOVA followed by Tukey's correction for post-hoc comparisons were performed for $\mathbf{A}-\mathbf{H}$. CCK-8 cell counting kit-8, ERK extracellular signal-regulated kinase, JNK c-Jun N-terminal kinase, MAPK mitogen-activated protein kinase, si-NC negative control short interfering RNAs (siRNA), si-Notch4 siRNA against Notch4, vector negative control plasmid, Notch4 Notch4 plasmid
} 

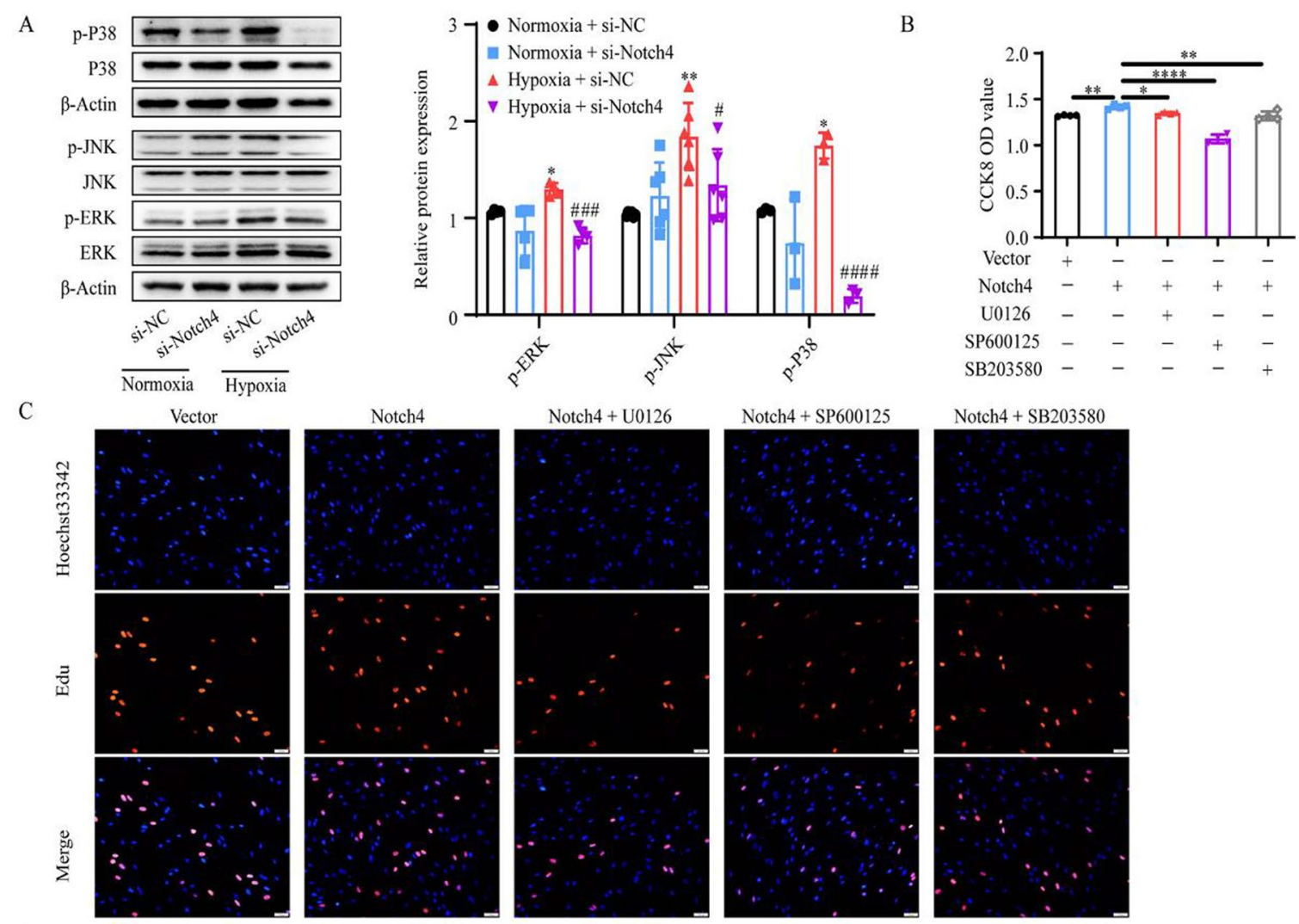

D
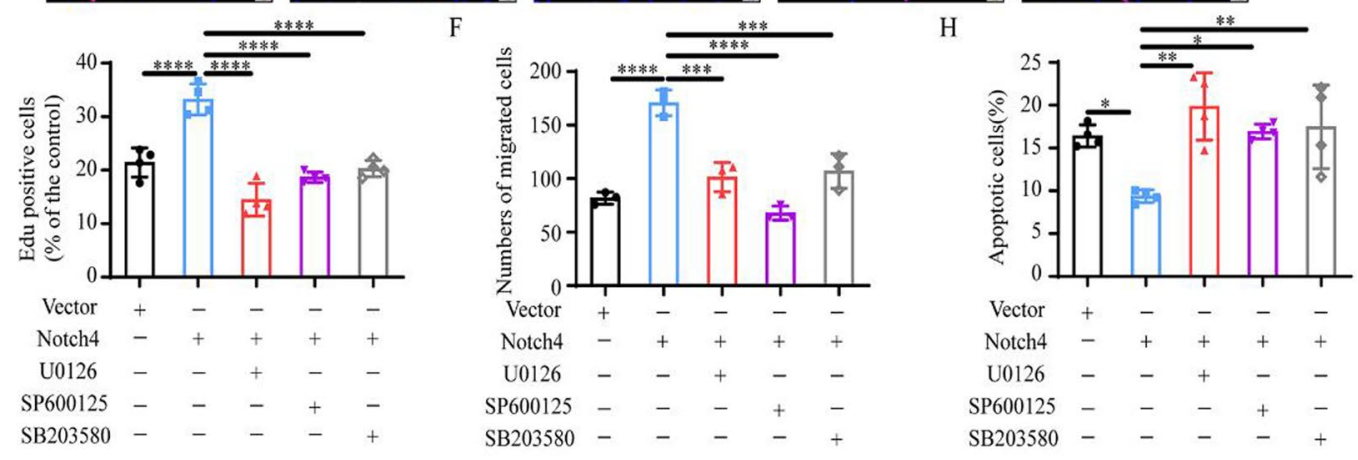

E

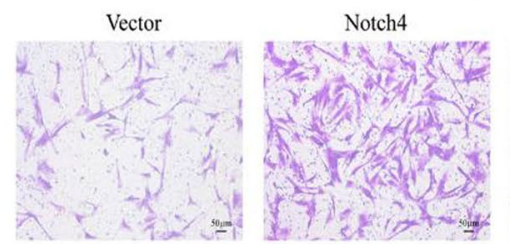

G
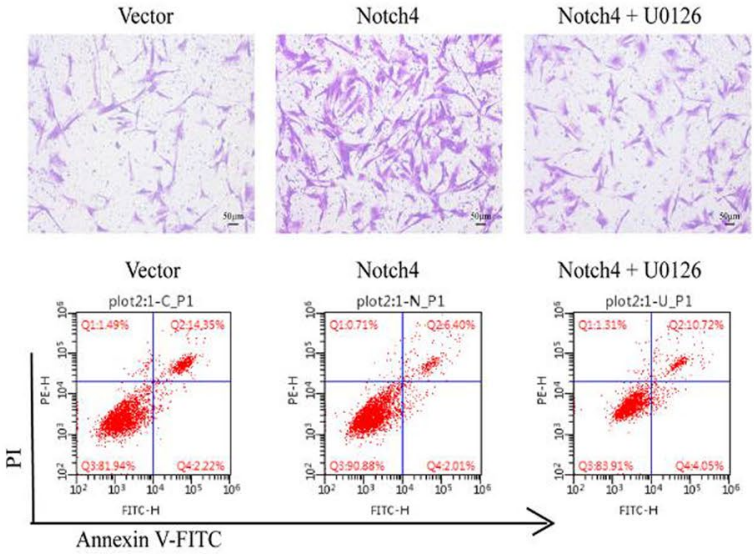

Notch4 + SP600125
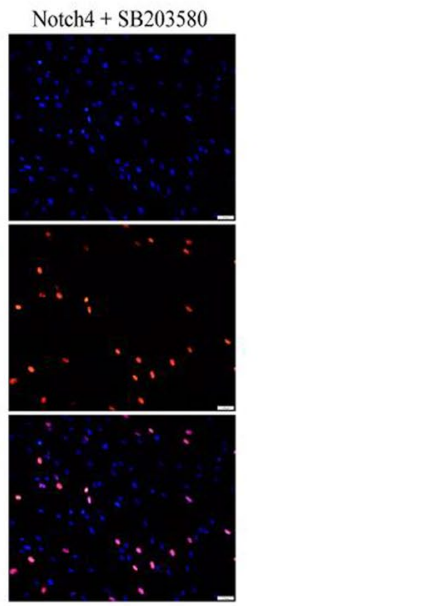

Fig. 3 (See legend on previous page.)
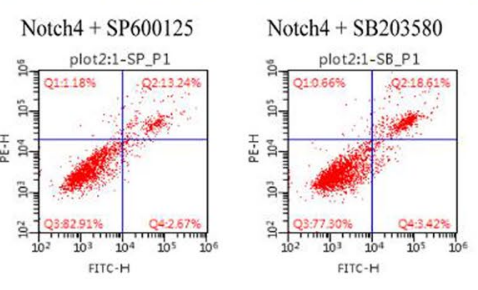
ERK, JNK, and P38 signaling pathways mediate the regulation of Notch4 on HPASMCs proliferation, apoptosis, and migration

The experiments described above implicate that Notch4 signaling mediate the effect of hypoxia on HPASMCs proliferation, apoptosis, and migration. We next explored the molecular mechanisms in the process. The level of Notch4 overexpression was determined by qRT-PCR and Western blotting (Additional file 1: Fig. S3). Notch4 overexpression promoted HPASMCs proliferation and migration, and inhibited cell apoptosis (Fig. 3B-H). The interaction between Notch4 and MAPK pathway in hypoxia HPASMCs was investigated. Hypoxia upregulated the phosphorylation of ERK, JNK, and P38 in HPASMCs, which were partially abrogated by transfection of siRNA against Notch4 (Fig. 3A). Meanwhile, the specific inhibitors of ERK, JNK, and P38 pathways (U0126, SP600125, or SB203580) partially abrogated the excessive proliferation and migration, and apoptosis resistance of HPASMCs induced by Notch4 overexpression (Fig. 3B-H). Furthermore, we assessed the expression of proteins associated with cell proliferation, apoptosis, and migration. Consistently, Notch4 overexpression increased protein expressions of survivin, PCNA, MMP2, and decreased the ratio of $\mathrm{Bax} / \mathrm{Bcl}$ 2 , which were partly restored by co-treatment with U0126, SP600125, or SB203580 (Fig. 4A-C). Taken together, our results demonstrate that MAPK pathway is responsible for mediating the effect of Notch4 on HPASMCs proliferation, apoptosis, and migration under hypoxia. The interaction between Notch4 and
ERK/JNK/P38 was confirmed using co-immunoprecipitation. The above results provide some clues for a novel crosstalk mechanism between non-canonical Notch signaling and MAPK pathway via interaction between Notch4 and ERK/JNK/P38 (Fig. 5A and B).

\section{Notch4 gene silence improves the hemodynamic parameters in $\mathrm{HPH}$ rats}

Our previous study has reported a rat model of pulmonary vascular remodeling exposed to hypoxia for 2 weeks [31]. An adeno-associated virus (AAV) 1encoded si-Notch4 was intratracheally delivered into the rats on day 0 and week 2 after hypoxic exposure in the prophylactic group and therapeutic group, respectively. We showed that AAV1-si-Notch4 can cross biological barriers and effectively achieve targeted pulmonary vascular media (Additional file 1: Fig. S4) and vSMCs-specifically silence Notch4 (Fig. 7B). The results showed that silencing Notch4 significantly reduced the RVSP of $\mathrm{HPH}$ rats measured by right cardiac catheterization (Fig. 6A and B). There was no significant difference in systematic arterial blood pressure among all the groups (Fig. 6C).

\section{Notch4 gene silence prevents and attenuates pulmonary vascular remodeling in $\mathrm{HPH}$ rats}

The prevention and attenuation of hypoxia-induced vascular remodeling by airway luminal delivery of AAV1-siNotch4 was assessed by hematoxylin and eosin staining, immunohistochemistry staining for $\alpha$-smooth muscle

\footnotetext{
(See figure on next page.)

Fig. 4 The regulation of Notch4 on the protein levels associated with proliferation, apoptosis and migration through ERK, JNK, or P38 MAPK pathway. A Protein levels of survivin, PCNA, Bax, BCl-2, ERK, p-ERK, MMP2, and Notch4 were determined in HPASMCs transfected with negative control plasmid or Notch4 plasmid together with U0126 for $24 \mathrm{~h}$. Bars show mean fold change of vector or as indicated. ( $n=4)$ B Protein levels of survivin, PCNA, Bax, BCl-2, JNK, p-JNK, MMP2, MMP9, and Notch4 were determined in HPASMCs transfected with negative control plasmid or Notch4 plasmid together with SP600125 for $24 \mathrm{~h}$. Bars show mean fold change of vector or as indicated. $(n=4)$ C Protein levels of survivin, $P C N A, B a x, B C l-2$, JNK, p-JNK, MMP2, and Notch4 were determined in HPASMCs transfected with negative control plasmid or Notch4 plasmid together with SB203580 for $24 \mathrm{~h}$. Bars show mean fold change of vector or as indicated. $(n=3)$ Data were presented as means $\pm S D .{ }^{*} P<0.05,{ }^{* *} P<0.01,{ }^{* * *} P<0.001$, ${ }^{* * *} P<0.0001$, comparison with HPASMCs transfected with negative control plasmid; ${ }^{*} P<0.05,{ }^{\#} P<0.01,{ }^{\# \#} P<0.001,{ }^{\# \# \#} P<0.0001$, comparison with HPASMCs transfected with Notch4 plasmid. One-way ANOVA followed by Tukey's correction for post-hoc comparisons were performed for A-C. ERK extracellular signal-regulated kinase, JNK c-Jun N-terminal kinase, MAPK mitogen-activated protein kinase, vector negative control plasmid, Notch4 Notch4 plasmid
} 

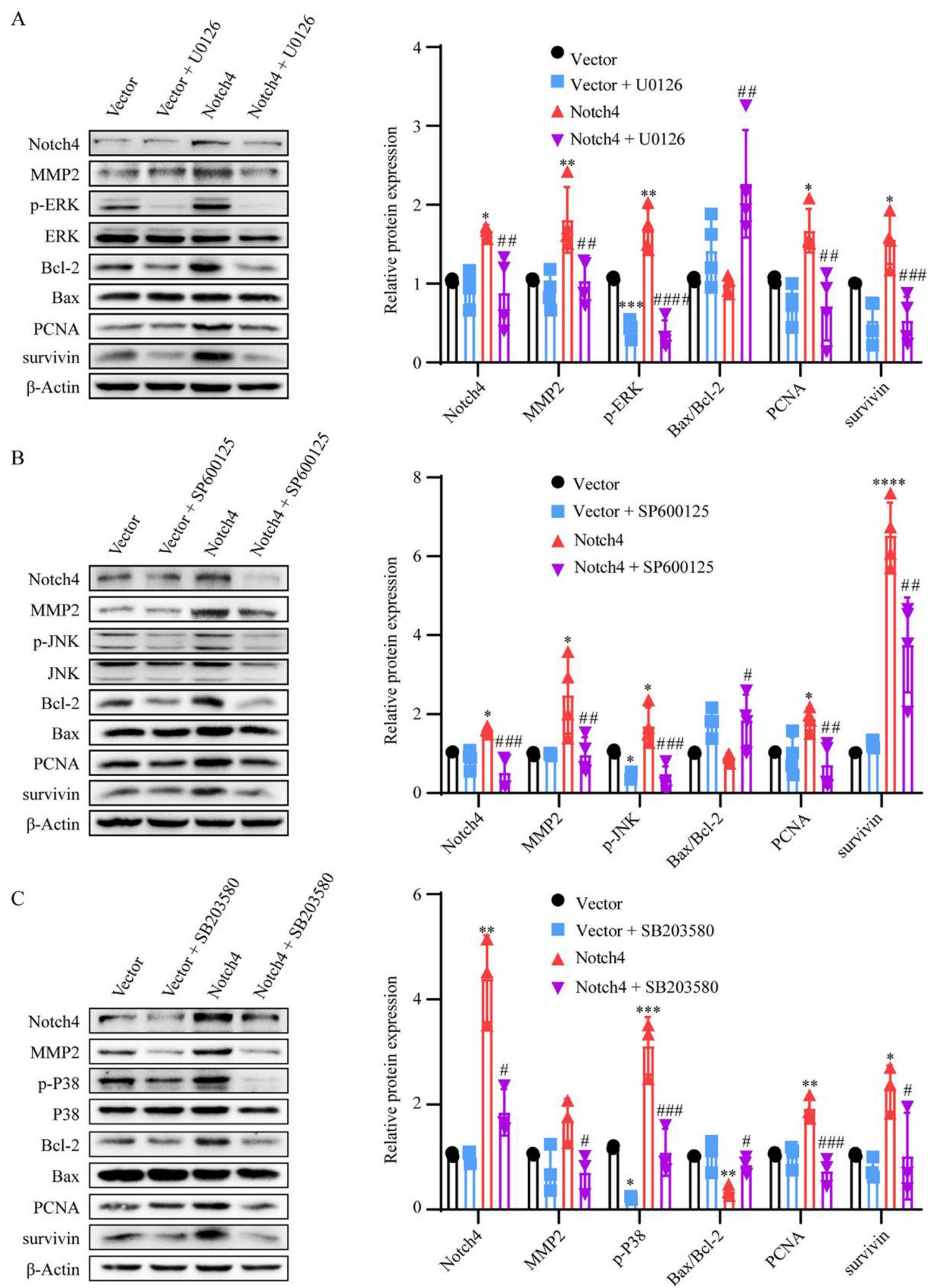

Fig. 4 (See legend on previous page.) 
A

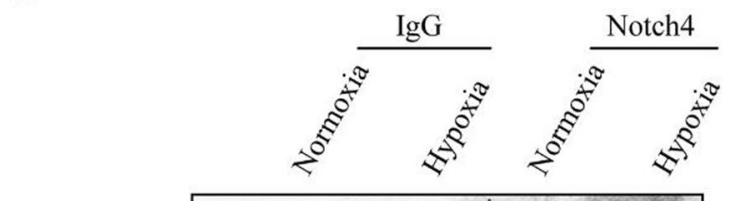

IP: Notch4

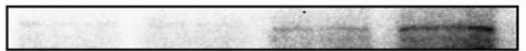

IB:



Normoxia Hypoxia

Input

WB:

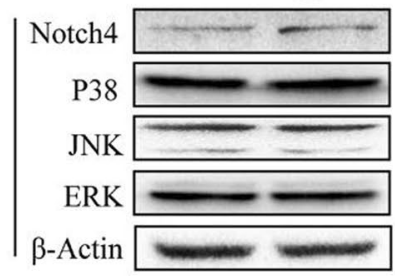

B

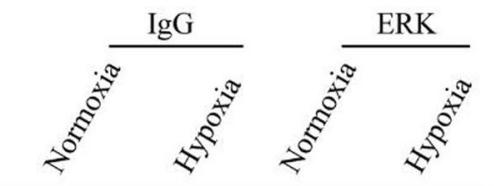

IP：ERK

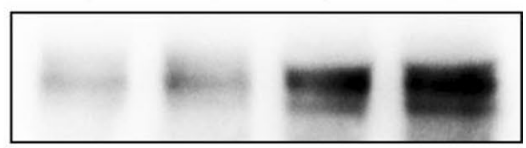

IB: Notch4


IP：JNK

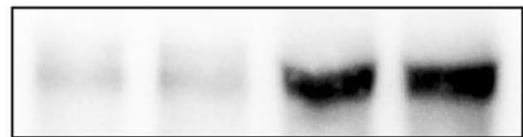

IB: Notch4
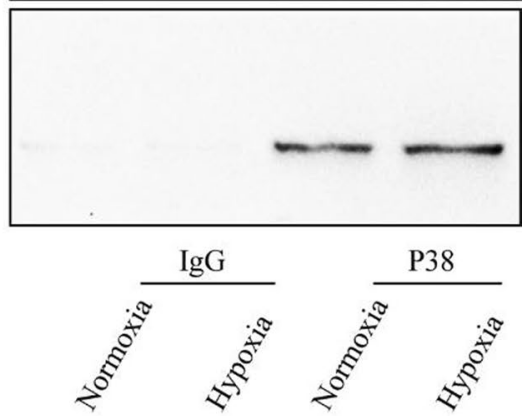

IP：P38

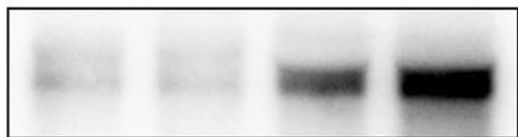

IB: Notch4

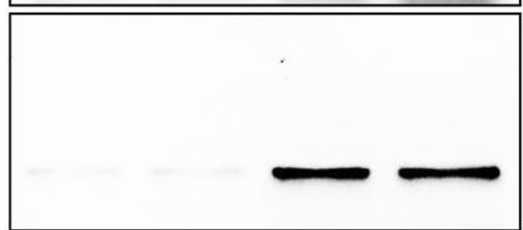

Normoxia Hypoxia

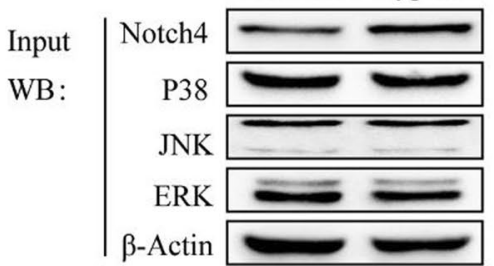

Fig. 5 Notch4 interacts with ERK, JNK, and P38 in HPASMCs. Endogenous co-immunoprecipitation was performed in HPASMCs exposed to normoxia or hypoxia for $24 \mathrm{~h}$. ERK extracellular signal-regulated kinase, JNK c-Jun $\mathrm{N}$-terminal kinase 
actin (Fig. 7A), RV hypertrophy assessed by RV/(LV + S) weight and RV/BW weight (Fig. 6D and E). Consistently, the protein levels of p-ERK, p-JNK, and p-P38 were decreased in the pulmonary artery in $\mathrm{HPH}$ rats treated with AAV1-si-Notch4 compared with negative controls (Fig. 7C).

\section{Discussion}

Notch4 is located and upregulated in pulmonary vascular smooth muscle from patients with HPH and HPH rats. In vitro, hypoxia induces the high expression of Delta-4 and Notch4 in HPASMCs. The increased expression of Notch4 promotes HPASMCs proliferation and migration and inhibits cells apoptosis via ERK, JNK, P38 signaling pathways. In vivo, AAV1-mediated gene silencing of Notch4 significantly reduced RVSP, and attenuated pulmonary vascular remodeling and RV hypertrophy in HPH rats. Our results establish a link between Notch4 signaling and MAPK pathway involved in PASMCs proliferation, apoptosis, and migration, and reveal a novel molecular regulatory axis that plays an essential role in the pathogenesis of $\mathrm{HPH}$.

Notch receptors are critical for controlling vSMCs differentiation and phenotypic transformation [32], which contributes to vascular remodeling [33]. A study reported that the constitutive active intracellular domain of Notch1, Notch2, or Notch4 receptors induced smooth muscle alpha-actin expression [34]. In this study, Notch4 was localized in the media and intimal layer of pulmonary small artery and the expression of Notch4 in the media was upregulated in patients with $\mathrm{HPH}$ and $\mathrm{HPH}$ rats compared with controls, which supports for the role of Notch4 in the pathogenesis of hypoxic pulmonary vascular remodeling.

Hypoxia activates the notch signaling pathway in cancer cells and nonmalignant cell types (such as intervertebral disc cells, Müller cells and astrocytes) $[35,36]$. Hypoxia inducible factor $1-\alpha$, a mediator of oxygen sensing, has been found to interact with Notch intracellular domain and act as a co-enhancer to stimulate transcription of Notch target genes under hypoxic conditions [37]. In this study, we reported a high expression of Notch4 in PASMCs both in vivo and in vitro, consistent with the previous study [38]. Knockdown of Notch4 partially abrogated the excessive HPASMCs proliferation, migration, and apoptosis resistance due to hypoxia. Thus, Notch4 is required in the process of hypoxia-induced vascular remodeling.

Notch receptors can affect cell proliferation, apoptosis, and migration via interacting with other nuclear transcription factors (NF-kB [39], Smad3 [40]) or other intracellular signaling (Wnt/ $\beta$-catenin [41], Akt [29]). MAPK signaling pathway, as an important intracellular signal transduction pathway, plays an important role in hypoxic pulmonary vascular remodeling. Activation of Notch1 signaling has been found to enhance MAPK activity via Notch1/MAML cascademediated transcription, and then induced melanoma cell growth [42]. In our study, in vivo and in vitro studies indicate that hypoxia upregulates Notch4 and activates ERK, JNK, and P38 pathways in hypoxic HPASMCs and rats pulmonary vascular. Knockdown of Notch4 suppressed the phosphorylation of ERK, JNK, and P38 in HPASMCs, and inhibited excessive

(See figure on next page.)

Fig. 6 Intratracheal delivery of AAV1.Notch4 improves pulmonary hemodynamics in the hypoxic PH rats compared with negative controls. A, B The preventive and therapeutic efficacy of AAV1.Notch4 were assessed by right ventricular systolic pressure (RVSP). C Blood pressure (BP) were measured in rats treated with AAV1.Notch4 or AAV1.NC under normoxic or hypoxic condition. D RV hypertrophy was determined by the RV/ $(\mathrm{LV}+\mathrm{S})$ weight ratio. E RV hypertrophy was determined by the RV/BW ratio. Data were presented as means $\pm \mathrm{SD} .{ }^{*} P<0.05,{ }^{* *} P<0.01,{ }^{* * *} P<0.001$, ${ }^{* * *} P<0.0001$. One-way ANOVA followed by Tukey's correction for post-hoc comparisons were performed for $\mathbf{B}-\mathbf{E}$. AAV adeno-associated virus, $P H$ pulmonary hypertension, $R V S P$ right ventricular systolic pressure, $R V$ right ventricle, $L V$ left ventricle, $B W$ body weight, $S$ septum, $P$ prevention, $T$ treatment 


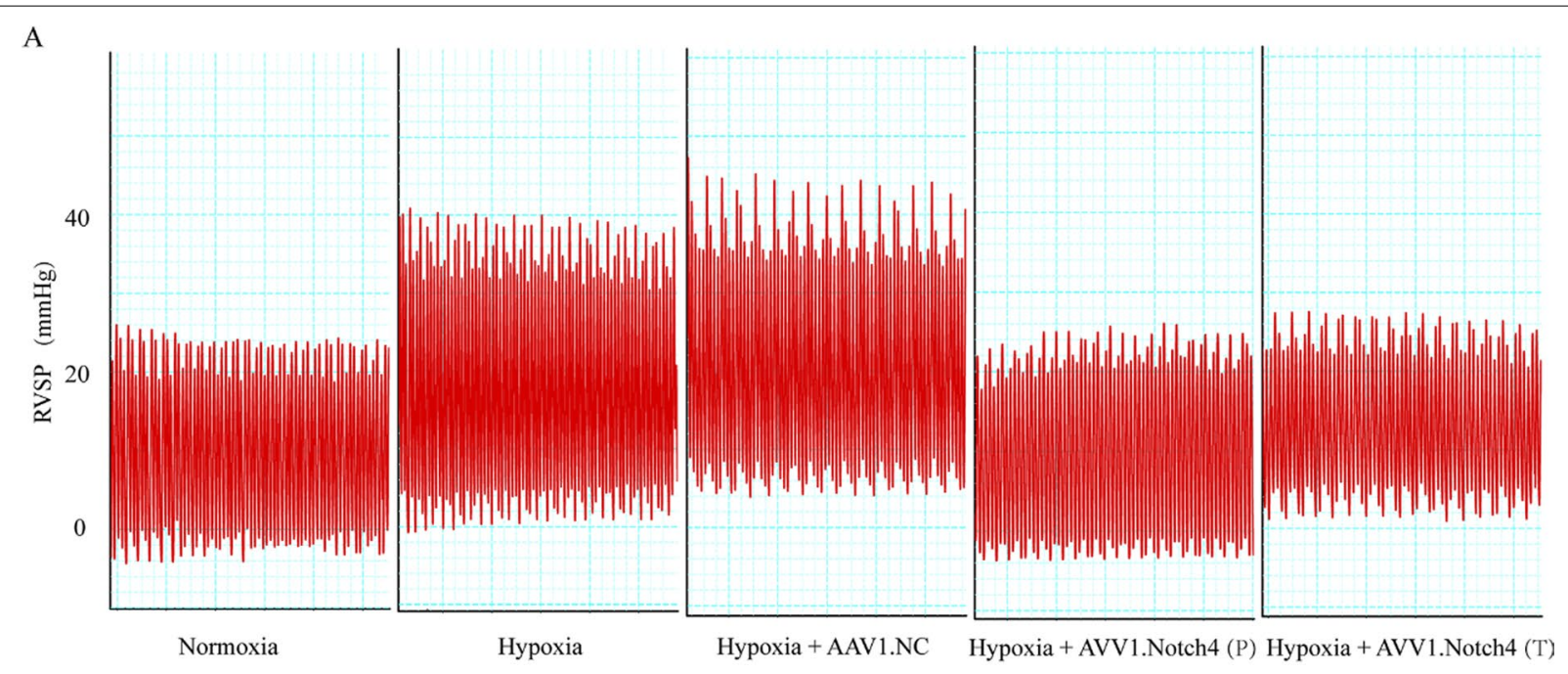

B

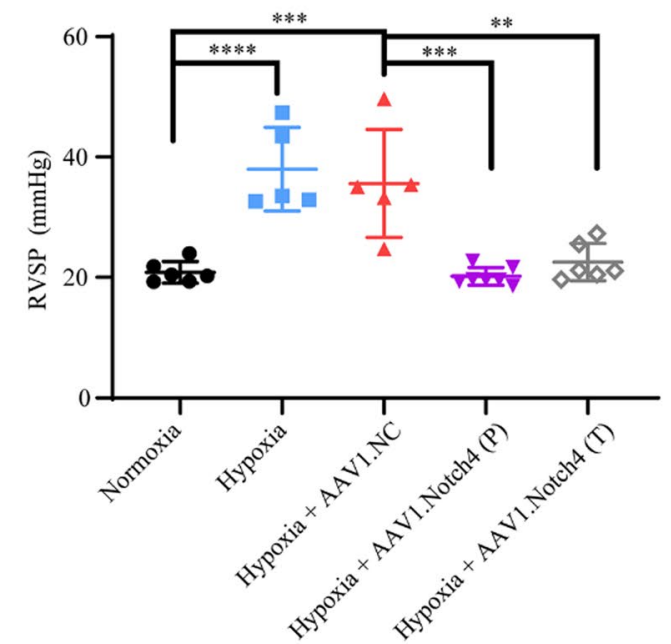

D

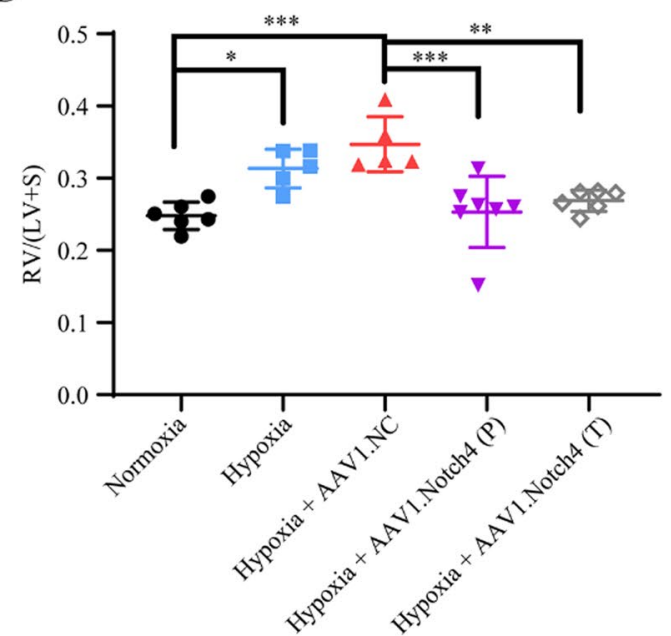

C

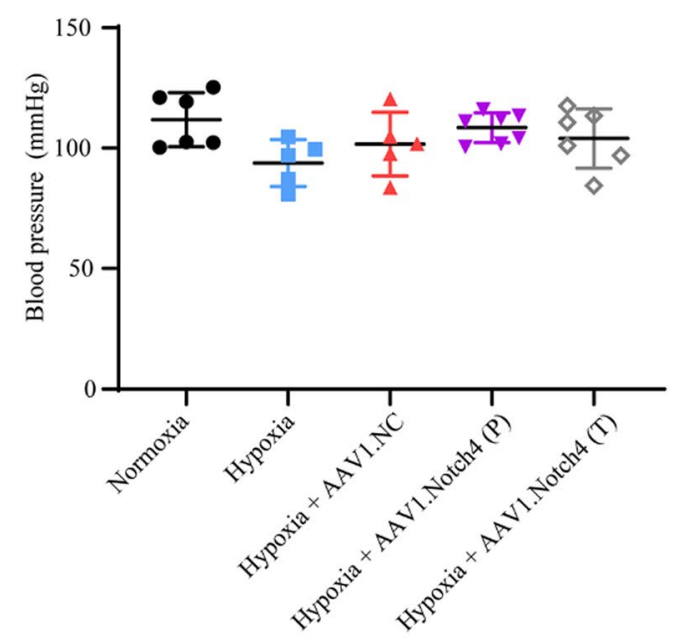

E

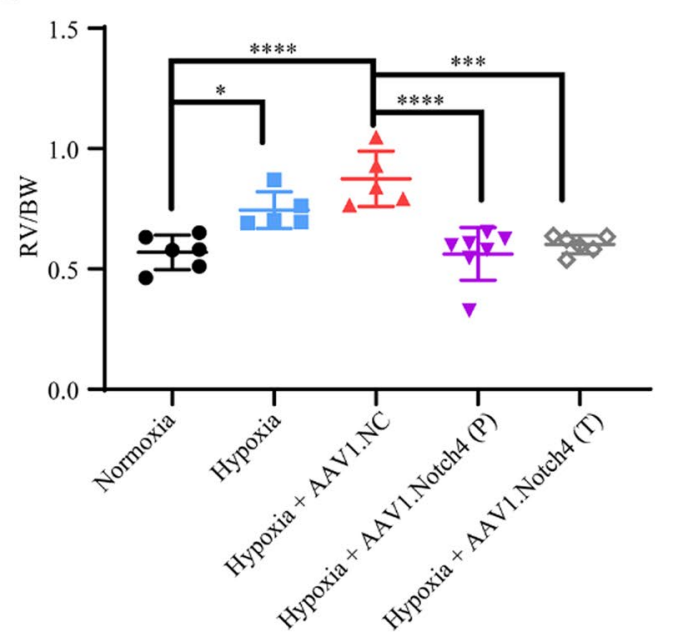

Fig. 6 (See legend on previous page.) 
cell proliferation and migration and induced cell apoptosis. Meanwhile, Notch4 knockdown partially reversed hypoxic pulmonary vascular remodeling. Furthermore, the MAPK inhibitors targeting ERK [43], JNK [44], and P38 [45] can significantly reverse the excessive proliferation and migration and inhibited apoptosis induced by Notch 4 overexpression. The above results suggest that the MAPK signaling pathway mediates the regulation of Notch4 on HPASMCs proliferation, apoptosis, and migration. Moreover, Notch4 was observed to interact with ERK/JNK/P38 by co-immunoprecipitation assay.

The safety represents a significant concern in gene therapy. In recent years, recombinant AAV has attracted great interest as a gene therapy vector because of stable expression of transgene without disturbing the function of the host genome [46]. AAV1 has a relative tropism for the heart (cardiomyocytes), and the endothelium, and vascular smooth muscle [30]. In this study, we used an AAV1 vector via intratracheal injection based on our previous work which demonstrated efficient transduction of AAV1 in pulmonary vessels [47]. Here, the intratracheal delivery of AAV1si-Notch 4 has both preventive and therapeutic efficacy in $\mathrm{HPH}$ rats. The AAV1 was highly expressed in the pulmonary vascular media of rat lung tissues. Notch4 expression was also vSMC-specifically silenced in the AAV1-si-Notch4 group.

There are some limitations to this study. Firstly, the western blotting result revealed an increased tendency of Notch4 in the lung tissues from 4 patients with $\mathrm{HPH}$ compared with matched controls. The power of the data is limited due to the insufficient sample size. Lung tissues from more HPH patients are needed for verification. Secondly, although the delivery of recombinant AAVs is promising, we must acknowledge the challenges here. The barrier concerns the immune response against the recombinant AAVs capsid, and poses substantial challenges to effective and safe gene delivery $[48,49]$. Thirdly, female rats are not included in our animal model. As Mair et al. has demonstrated that endogenous estrogen plays a causative role in the development of hypoxic pulmonary hypertension in female animal models [50]. In addition, the male rat models are widely used in the study of hypoxic pulmonary hypertension [51]. We investigated the role of Notch4 in the development of hypoxic pulmonary hypertension in the male rat models.

In conclusion, this study demonstrates an important role of the Notch4-ERK/JNK/P38 MAPK axis in hypoxic pulmonary remodeling and provides a potential therapeutic target for $\mathrm{HPH}$ patients.

\section{Conclusions}

This study reveals an important role of the Notch4-ERK/ JNK/P38 MAPK axis in hypoxic pulmonary remodeling and provides a potential therapeutic target for patients with $\mathrm{HPH}$.

\footnotetext{
(See figure on next page.)

Fig. 7 Notch4 gene silence alleviates pulmonary artery remodeling. A Hematoxylin-eosin staining and immunohistochemistry staining for a-smooth muscle actin, in lung sections of rats treated with AAV1.Notch4 or AAV1.NC under normoxic or hypoxic condition ( $\mathrm{n}=5-7$ ). Magnification, $\times$ 200; Bar, 50 Mm. B Notch4 (red) and a-SMA (green) immunofluorescence staining in small pulmonary arteries in rat lung tissues. Nuclei are counterstained with DAPI (blue). Magnification, $\times$ 400; Bar, 20 m. C Protein expression of Notch4, p-ERK, ERK, p-JNK, JNK, p-P38, P38 in pulmonary artery in rats treated with AAV1.Notch4 or AAV1.NC under normoxic or hypoxic condition $(n=4)$. Data were presented as means \pm SD. ${ }^{*} P<0.05,{ }^{* *} P<0.01,{ }^{* *} P<0.001,{ }^{* * *} P<0.0001$. One-way ANOVA followed by Tukey's correction for post-hoc comparisons were performed for $\mathbf{A}$ and $\mathbf{C}$. H\&E hematoxylin-eosin staining, a-SMA a-smooth muscle actin, AAV adeno-associated virus, ERK extracellular signal-regulated kinase, JNK c-Jun N-terminal kinase
} 


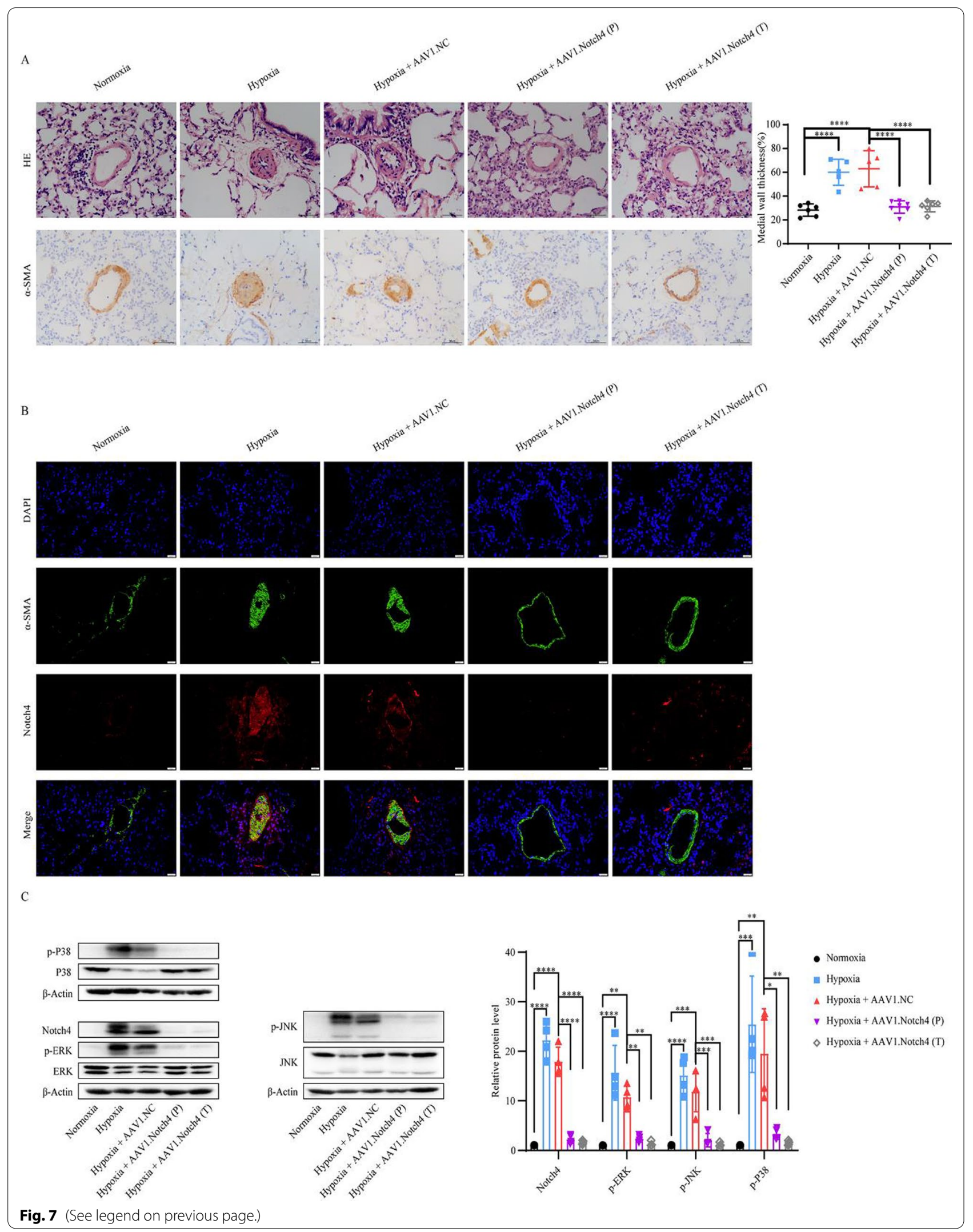




\section{Abbreviations}

HPH: Hypoxic pulmonary hypertension; PH: Pulmonary hypertension; vSMCs: Vascular smooth muscle cells; PASMCs: Pulmonary artery smooth muscle cells; HPASMCs: Human pulmonary artery smooth muscle cells; ERK: Extracellular signal-regulated kinase; JNK: C-Jun N-terminal kinase; MAPK: Mitogenactivated protein kinase; RVSP: Right ventricular systolic pressure; PCNA: Polyclonal antibodies against proliferating cell nuclear antigen; $\mathrm{BCl}-2$ : B cell leukemia/lymphoma 2; Bax: BCL2 associated X; MMP9: Matrix metallopeptidase 9; MMP2: Matrix metallopeptidase 2; IgG: Immunoglobulin G; siRNA: Small interfering RNA; AAV: Adeno-associated virus.

\section{Supplementary Information}

The online version contains supplementary material available at https://doi. org/10.1186/s12931-022-01927-9.

Additional file 1. Notch4 mediates vascular remodeling via ERK/JNK/P38 MAPK signaling pathways in hypoxic pulmonary hypertension.

\section{Acknowledgements}

Not applicable.

\section{Authors' contributions}

$\mathrm{XL}$ conceived the study and revised the manuscript. MG performed the experiments and drafted the manuscript. $\mathrm{XC}$ and $\mathrm{YH}$ revised the article. $\mathrm{MZ}$, $X F, K L, L Q$ provided assistance in animal experiments. JZ, YX, XL provided intellectual input and revised the article. All authors read and approved the final manuscript.

\section{Funding}

This work was supported by Grants from National Natural Science Foundation of China (81700052)

\section{Availability of data and materials}

The datasets used and/or analyzed during the current study are available from the corresponding author on reasonable request.

\section{Declarations}

\section{Ethics approval and consent to participate}

All animal experiments were performed in compliance with the guidelines for animal testing and research, with ethical approval from Tongji Hospital. All patients were enrolled from Tongji Hospital of Huazhong University of Science and Technology (Wuhan, China). This study was approved by the Ethics Committee of Tongji Hospital and. Written informed consent was obtained from each patient.

\section{Consent for publication}

Not applicable.

\section{Competing interests}

All authors declare that they have no competing interests.

\section{Author details}

'Department of Pulmonary and Critical Care Medicine, Tongji Hospital, Tongji Medical College, Huazhong University of Science and Technology, 1095 Jiefang Avenue, Wuhan 430030, China. ${ }^{2}$ Key Laboratory of Respiratory Diseases, National Ministry of Health of the People's Republic of China and National Clinical Research Center for Respiratory Disease, Wuhan, China. ${ }^{3}$ Department of Pediatrics, Tongji Hospital, Tongji Medical College, Huazhong University of Science and Technology, Wuhan, China.

Received: 3 November 2021 Accepted: 3 January 2022

Published online: 11 January 2022

\section{References}

1. Hoeper MM, Ghofrani HA, Grünig E, Klose H, Olschewski H, Rosenkranz S. Pulmonary hypertension. Dtsch Arztebl Int. 2017;114:73-84.

2. Chen J, Sysol JR, Singla S, Zhao S, Yamamura A, Valdez-Jasso D, et al. Nicotinamide phosphoribosyltransferase promotes pulmonary vascular remodeling and is a therapeutic target in pulmonary arterial hypertension. Circulation. 2017:135:1532-46.

3. Schermuly RT, Ghofrani HA, Wilkins MR, Grimminger F. Mechanisms of disease: pulmonary arterial hypertension. Nat Rev Cardiol. 2011:8:443-55.

4. Galiè N, Humbert M, Vachiery JL, Gibbs S, Lang I, Torbicki A, et al. 2015 ESC/ERS Guidelines for the diagnosis and treatment of pulmonary hypertension: the Joint Task Force for the Diagnosis and Treatment of Pulmonary Hypertension of the European Society of Cardiology (ESC) and the European Respiratory Society (ERS): endorsed by: Association for European Paediatric and Congenital Cardiology (AEPC), International Society for Heart and Lung Transplantation (ISHLT). Eur Heart J. 2016;37:67-119.

5. Pagliaro L, Marchesini M, Roti G. Targeting oncogenic Notch signaling with SERCA inhibitors. J Hematol Oncol. 2021;14:8.

6. Artavanis-Tsakonas S, Rand MD, Lake RJ. Notch signaling: cell fate control and signal integration in development. Science. 1999;284:770-6.

7. Bray SJ. Notch signalling in context. Nat Rev Mol Cell Biol. 2016;17:722-35.

8. Ramakrishnan G, Davaakhuu G, Chung WC, Zhu H, Rana A, Filipovic A, et al. AKT and 14-3-3 regulate Notch4 nuclear localization. Sci Rep. 2015:5:8782.

9. Mumm JS, Kopan R. Notch signaling: from the outside in. Dev Biol. 2000:228:151-65.

10. Baron M. An overview of the Notch signalling pathway. Semin Cell Dev Biol. 2003:14:113-9.

11. Meester JAN, Verstraeten A, Alaerts M, Schepers D, Van Laer L, Loeys BL. Overlapping but distinct roles for NOTCH receptors in human cardiovascular disease. Clin Genet. 2019;95:85-94.

12. Noseda M, McLean G, Niessen K, Chang L, Pollet I, Montpetit R, et al. Notch activation results in phenotypic and functional changes consistent with endothelial-to-mesenchymal transformation. Circ Res. 2004:94:910-7.

13. Sasnauskienè $A$, Jonušienè $V$, Krikštaponienè $A$, Butkytè $S$, Dabkevičiené D, Kanopienè D, et al. NOTCH1, NOTCH3, NOTCH4, and JAG2 protein levels in human endometrial cancer. Medicina (Kaunas). 2014;50:14-8.

14. Nagamatsu I, Onishi H, Matsushita S, Kubo M, Kai M, Imaizumi A, et al. NOTCH4 is a potential therapeutic target for triple-negative breast cancer. Anticancer Res. 2014:34:69-80.

15. Hardy KM, Kirschmann DA, Seftor EA, Margaryan NV, Postovit LM, Strizzi $L$, et al. Regulation of the embryonic morphogen Nodal by Notch4 facilitates manifestation of the aggressive melanoma phenotype. Cancer Res. 2010;70:10340-50.

16. Amarir S, Marx M, Calothy G. Notch signaling activation suppresses $v$-Src-induced transformation of neural cells by restoring TGF- $\beta$-mediated differentiation. PLoS ONE. 2010;5:e13572.

17. Gutierrez A, Look AT. NOTCH and PI3K-AKT pathways intertwined. Cancer Cell. 2007:12:411-3.

18. Zavadil J, Cermak L, Soto-Nieves N, Böttinger EP. Integration of TGF-beta/ Smad and Jagged1/Notch signalling in epithelial-to-mesenchymal transition. Embo j. 2004;23:1155-65.

19. Kim EK, Choi EJ. Compromised MAPK signaling in human diseases: an update. Arch Toxicol. 2015;89:867-82.

20. Wei L, Liu Y, Kaneto H, Fanburg BL. JNK regulates serotonin-mediated proliferation and migration of pulmonary artery smooth muscle cells. Am J Physiol Lung Cell Mol Physiol. 2010;298:L863-869.

21. Jin N, Hatton N, Swartz DR, Xia X, Harrington MA, Larsen SH, et al. Hypoxia activates jun-N-terminal kinase, extracellular signal-regulated protein kinase, and p38 kinase in pulmonary arteries. Am J Respir Cell Mol Biol. 2000;23:593-601.

22. Das M, Bouchey DM, Moore MJ, Hopkins DC, Nemenoff RA, Stenmark KR Hypoxia-induced proliferative response of vascular adventitial fibroblasts is dependent on g protein-mediated activation of mitogen-activated protein kinases. J Biol Chem. 2001;276:15631-40. 
23. Yu X, Li T, Liu X, Yu H, Hao Z, Chen Y, et al. Modulation of pulmonary vascular remodeling in hypoxia: role of 15-LOX-2/15-HETE-MAPKs pathway. Cell Physiol Biochem. 2015:35:2079-97.

24. Yan S, Wang Y, Liu P, Chen A, Chen M, Yao D, et al. Baicalin attenuates hypoxia-induced pulmonary arterial hypertension to improve hypoxic cor pulmonale by reducing the activity of the p38 MAPK signaling pathway and MMP-9. Evid Based Complement Alternat Med. 2016;2016:2546402

25. Tian $H$, Liu L, Wu Y, Wang R, Jiang Y, Hu R, et al. Resistin-like molecule beta acts as a mitogenic factor in hypoxic pulmonary hypertension via the $\mathrm{Ca}(2+)$-dependent PI3K/Akt/mTOR and PKC/MAPK signaling pathways. Respir Res. 2021;22:8.

26. MacKenzie F, Duriez P, Wong F, Noseda M, Karsan A. Notch4 inhibits endothelial apoptosis via RBP-Jkappa-dependent and -independent pathways. J Biol Chem. 2004;279:11657-63

27. Kiec-Wilk B, Grzybowska-Galuszka J, Polus A, Pryjma J, Knapp A, Kristiansen K. The MAPK-dependent regulation of the Jagged/Notch gene expression by VEGF, bFGF or PPAR gamma mediated angiogenesis in HUVEC. J Physiol Pharmacol. 2010;61:217-25.

28. Lai PY, Tsai CB, Tseng MJ. Active form Notch4 promotes the proliferation and differentiation of 3T3-L1 preadipocytes. Biochem Biophys Res Commun. 2013;430:1132-9.

29. Qian CJ, Chen YY, Zhang X, Liu FQ, Yue TT, Ye B, et al. Notch4 inhibition reduces migration and invasion and enhances sensitivity to docetaxel by inhibiting Akt/fascin in pancreatic cancer cells. Oncol Lett. 2016;12:3499-505.

30. Hadri L, Kratlian RG, Benard L, Maron BA, Dorfmüller P, Ladage D, et al. Therapeutic efficacy of AAV1.SERCA2a in monocrotaline-induced pulmonary arterial hypertension. Circulation. 2013;128:512-23.

31. Li $X$, He $Y, X u Y$, Huang $X$, Liu J, Xie M, et al. KLF5 mediates vascular remodeling via HIF-1alpha in hypoxic pulmonary hypertension. Am J Physiol Lung Cell Mol Physiol. 2016;310:L299-310.

32. Morris HE, Neves KB, Montezano AC, MacLean MR, Touyz RM. Notch3 signalling and vascular remodelling in pulmonary arterial hypertension. Clin Sci (Lond). 2019;133:2481-98.

33. Alexander MR, Owens GK. Epigenetic control of smooth muscle cell differentiation and phenotypic switching in vascular development and disease. Annu Rev Physiol. 2012;74:13-40.

34. Tang Y, Urs S, Liaw L. Hairy-related transcription factors inhibit Notchinduced smooth muscle alpha-actin expression by interfering with Notch intracellular domain/CBF-1 complex interaction with the CBF-1-binding site. Circ Res. 2008:102:661-8.

35. Sahlgren C, Gustafsson MV, Jin S, Poellinger L, Lendahl U. Notch signaling mediates hypoxia-induced tumor cell migration and invasion. Proc Natl Acad Sci U S A. 2008;105:6392-7.

36. Hiyama A, Skubutyte R, Markova D, Anderson DG, Yadla S, Sakai D, et al. Hypoxia activates the notch signaling pathway in cells of the intervertebral disc: implications in degenerative disc disease. Arthritis Rheum. 2011;63:1355-64

37. Gustafsson MV, Zheng X, Pereira T, Gradin K, Jin S, Lundkvist J, et al. Hypoxia requires notch signaling to maintain the undifferentiated cell state. Dev Cell. 2005;9:617-28.

38. Qiao L, Xie L, Shi K, Zhou T, Hua Y, Liu H. Notch signaling change in pulmonary vascular remodeling in rats with pulmonary hypertension and its implication for therapeutic intervention. PLoS ONE. 2012;7:e51514.

39. Zhang J, Kuang $Y$, Wang $Y, X u$ Q, Ren Q. Notch-4 silencing inhibits prostate cancer growth and EMT via the NF-kB pathway. Apoptosis. 2017;22:877-84

40. Sun Y, Lowther W, Kato K, Bianco C, Kenney N, Strizzi L, et al. Notch4 intracellular domain binding to Smad3 and inhibition of the TGF-beta signaling. Oncogene. 2005;24:5365-74.

41. Qian C, Liu F, Ye B, Zhang X, Liang Y, Yao J. Notch4 promotes gastric cancer growth through activation of Wnt1/beta-catenin signaling. Mol Cell Biochem. 2015;401:165-74.

42. Liu ZJ, Xiao M, Balint K, Smalley KS, Brafford P, Qiu R, et al. Notch1 signaling promotes primary melanoma progression by activating mitogenactivated protein kinase/phosphatidylinositol 3-kinase-Akt pathways and up-regulating N-cadherin expression. Cancer Res. 2006;66:4182-90.

43. Favata MF, Horiuchi KY, Manos EJ, Daulerio AJ, Stradley DA, Feeser WS, et al. Identification of a novel inhibitor of mitogen-activated protein kinase kinase. J Biol Chem. 1998;273:18623-32.
44. Bennett BL, Sasaki DT, Murray BW, O'Leary EC, Sakata ST, Xu W, et al. SP600125, an anthrapyrazolone inhibitor of Jun $\mathrm{N}$-terminal kinase. Proc Natl Acad Sci U S A. 2001;98:13681-6.

45. Cuenda A, Rouse J, Doza YN, Meier R, Cohen P, Gallagher TF, et al. SB 203580 is a specific inhibitor of a MAP kinase homologue which is stimulated by cellular stresses and interleukin-1. FEBS Lett. 1995;364:229-33.

46. Hajjar RJ. Potential of gene therapy as a treatment for heart failure. J Clin Invest. 2013;123:53-61.

47. Sun D, Ding D, Li Q, Xie M, Xu Y, Liu X. The preventive and therapeutic effects of AAV1-KLF4-shRNA in cigarette smoke-induced pulmonary hypertension. J Cell Mol Med. 2021;25:1238-51.

48. Vandamme C, Adjali O, Mingozzi F. Unraveling the complex story of immune responses to AAV vectors trial after trial. Hum Gene Ther. 2017;28:1061-74

49. Mingozzi F, High KA. Overcoming the host immune response to adenoassociated virus gene delivery vectors: the race between clearance, tolerance, neutralization, and escape. Annu Rev Virol. 2017:4:511-34.

50. Mair KM, Wright AF, Duggan N, Rowlands DJ, Hussey MJ, Roberts S, et al. Sex-dependent influence of endogenous estrogen in pulmonary hypertension. Am J Respir Crit Care Med. 2014;190:456-67.

51. Xu SL, Deng YS, Liu J, Xu SY, Zhao FY, Wei L, et al. Regulation of circular RNAs act as ceRNA in a hypoxic pulmonary hypertension rat model. Genomics. 2021;113:11-9.

\section{Publisher's Note}

Springer Nature remains neutral with regard to jurisdictional claims in published maps and institutional affiliations.
Ready to submit your research? Choose BMC and benefit from:

- fast, convenient online submission

- thorough peer review by experienced researchers in your field

- rapid publication on acceptance

- support for research data, including large and complex data types

- gold Open Access which fosters wider collaboration and increased citations

- maximum visibility for your research: over 100M website views per year

At BMC, research is always in progress.

Learn more biomedcentral.com/submissions 